\title{
The Early Years of Teaching: A Cross-Cultural Study of Turkish and Polish Novice English Teachers*
}

\section{Müzeyyen Nazli Güngör a †(D), Sumru Akcan ${ }^{b}$ ‡(D), Dorota Werbinska ${ }^{c}$ (D), Malgorzata Ekiert ${ }^{\mathrm{*}}$ ** (1)}

${ }^{a}$ Gazi University, Department of Foreign Language Education, Ankara 06500, Turkey

${ }^{b}$ Boğaziçi University, Department of Foreign Language Education, Istanbul 34342, Turkey

c Pomeranian University, Institute of Modern Languages, Slupsk, Poland

Received 25 May 2019 | Received in revised form 11 June 2019 | Accepted 04 July 2019

\begin{abstract}
APA Citation:
Güngör, M. N., Akcan, S., Werbinska, D., \& Ekiert, M. (2019). The early years of teaching: A cross-cultural study of Turkish and Polish Novice English Teachers. Eurasian Journal of Applied Linguistics, 5(2), 287-302. Doi: 10.32601/ejal.599262
\end{abstract}

\begin{abstract}
Given the importance of novice teacher experiences and their long-term effects in the field, this crosscultural exploratory study investigates the challenges of 34 novice Turkish and Polish English teachers and how they develop their professional understanding in the early years of teaching. The participants were non-native novice English teachers working with K-12 learners in culturally, socially, economically and historically diverse regions of Turkey and Poland. The data collected simultaneously in both countries in the spring term of the 2016-17 academic year were generated from two sources: a) critical incidents of the novice teachers, and b) online and/or oral interviews with these teachers, followed by comprehensive cyclical data analysis. The challenges related to pedagogical and sociocultural factors influenced the way the teachers teach in their contexts. The findings suggest that creating interactive and reflective learning contexts for novice teachers will help them better adapt to their new school settings and develop professionally.
\end{abstract}

(C) 2019 EJAL \& the Authors. Published by Eurasian Journal of Applied Linguistics (EJAL). This is an open-access article distributed under the terms and conditions of the Creative Commons Attribution license (CC BY-NC-ND) (http://creativecommons.org/licenses/by-nc-nd/4.0/).

Keywords: Novice teachers; early years; challenges; critical incidents; professional understanding; diversity

\section{Introduction}

\footnotetext{
* This paper is presented at ATEE Conference in Sweden in 2018.

$\dagger$ Corresponding author. Tel.: +9-0312-202-8456

E-mail address: nazlidemirbas@gazi.edu.tr

‡ akcans@boun.edu.tr

§ dorota.werbinska@apsl.edu.pl

** malgorzata.ekiert@apsl.edu.pl
} 
Novice teachers, according to Farrell (2012), have started to teach English within three years of completing their pre-service teacher education programme. The initial years of teaching, often called a "reality shock" (Veenman, 1984), are critical for professional development (Farrell, 2009, 2012). As a result of globalization, marked technological changes, increased migration, and sociocultural and economic instability in many countries, today's students' needs and interests are diverse. Parallel to these changes, novice teachers experience unpredictable challenges, especially in their initial years (Madalinska-Michalak \& Bavli, 2018). This situation requires teacher education programmes to be reconsidered to help novice teachers develop their pedagogical knowledge, attitudes, and professional understanding, and raise, above all, their awareness of the realities in constantly changing learning environments (Darling-Hammond, 2017). The first years of teaching may have long-term implications for job satisfaction and career length (Cochran-Smith, 2004). Therefore, helping novice teachers develop coping strategies and skills to meet and overcome the challenges they encounter in their new workplace is considered vital.

\subsection{The Initial Years of Teaching}

A number of studies indicate that the professional challenges in initial years of teaching include stress (Richards \& Farrell, 2005), misunderstandings and isolation (Nias, 1996; Werbinska, 2011), teaching large classes, student demotivation, long working hours, (Madalinska-Michalak \& Bavli, 2018), teaching English with limited resources, difficulties in curriculum implementation, rural teaching, and teachers' inadequate competences (Copland, Garton, \& Burns, 2014; Kizilaslan, 2012). Teachers also express the need for more in-service professional development opportunities and activities consisting of more practical content and mentoring (Mann \& Tang, 2012). In addition, recent international studies have confirmed that meeting students' needs, cooperating with parents, dealing with classroom behaviour problems, assessing, motivating students, or collaborating with the school administration are among the challenges novice teachers encounter in their first years (Fantilli \& McDougall, 2009; Mann \& Tang, 2012). Pillen, Beijaard, and Brok (2013) note that the concerns of new teachers influence their relationships with students, classroom management skills and preferred instructional methods.

The research reported here is part of an Erasmus+ project which aims to encourage international cross-cultural research in second language teacher education. Although Turkish and Polish contexts include studies on novice teachers' reflections (Akcan, 2016), their experiences in initial years (Werbinska, 2011) and challenges of teaching English in Polish and Turkish context (Madalinska-Michalak \& Bavli, 2018), this study contributes to the field in terms of comparing cross-cultural differences and similarities in the first years of teaching and transforming their local challenges into global opportunities for other contexts. As both countries remarkably differ in terms of history, religion, culture and socio-political background, we found it interesting to explore how novice teachers of English in Poland and Turkey respond to early-career teaching experiences. The aim of this cross-cultural study is to investigate novice 
teachers' shared and divergent challenges in Poland and Turkey. The research questions which guided the study were:

1. What are the challenges experienced by Turkish and Polish novice language teachers and how do they diverge?

2. How do Turkish and Polish novice language teachers develop their professional understanding in the early years of teaching?

\section{Methodology}

\subsection{Research Context: Teaching English in Primary and Secondary Schools in Poland and Turkey}

In Poland, with the new core curriculum for foreign languages launched in 2017, English is also the most common language taught at all educational levels, including the $1^{\text {st }}$ grade of elementary school. Students usually have three hours of English per week, which is increased by two more hours in the last two years of primary school. Learning English is then continued throughout post-primary school, and many schools, especially at a secondary level, introduce extended English programmes in which the number of language hours is increased, or a few selected content subjects are delivered via English. Generally, the English language is viewed positively in Poland, and most people, especially those under 30, can easily communicate in English. Although immigration to Poland from the former Soviet Union countries has substantially increased in recent times, a typical Polish state school is still relatively homogenous in terms of the pupils' national and ethnic background or religion.

Contrary to Polish schools, state schools in Turkey are heterogeneous; not only attended by Turks but also by Kurds, Arabians, Persians, and Africans. Due to the threat of terrorism and war in Syria and other Arabic countries in recent years, Turkey has received many refugees and immigrants from these countries. Hence, Turkish teachers teach English to all these groups, which is one of the biggest challenges they encounter in their schools. In Turkey, English is the most common foreign language at schools. With the recent launch of the curriculum in 2012 (Kirkgoz, 2014), it is introduced in Grade 2 for two hours per week in public schools. The starting age for learning English as a foreign language in Turkey was reduced from 9 to 7 in 2012. The number of English lessons was defined as 2 hours in $2^{\text {nd }}, 3^{\text {rd }}$, and $4^{\text {th }}$ grades (primary years), then increased to 3 hours in $5^{\text {th }}$ and $6^{\text {th }}$ grades, and to 4 hours in $7^{\text {th }}$ and $8^{\text {th }}$ grades.

\subsection{Language Teacher Education Programmes in Poland and Turkey}

Language teacher education programmes in Poland offer undergraduate and graduate programmes. During their studies at both BA and MA levels, students attend courses in language teaching, language acquisition, advanced language skills and linguistics. At the end of their training, they are placed at primary (BA) or secondary (MA) schools as part of their language teaching practicum. Unlike pre- 
service teachers in Turkey, Polish candidates do not take any special examinations to become language teachers. They are selected locally by school principals provided they hold formal teaching qualifications. They can freely change their place of work if they wish and/or manage to find a vacancy for a language teacher's post at another school.

Teacher education in Turkey is comprised of undergraduate (BA) and graduate (MA and $\mathrm{PhD}$ ) programmes in English language teaching. Once admitted to university, teacher candidates study English for a year if they cannot pass the language proficiency exam. After they have passed the exam, they can enrol on the teacher education programme. In the programme, they are taught theoretical courses in linguistics, classroom management, language acquisition, as well as practical courses in teaching language skills, teaching young learners, assessment, school experience, and practice teaching. Upon the completion of the programme, they take part in a two-stage-examination system. The first part is the written national examination "Public personnel selection examination", which is followed by interviews conducted by expert teachers, school administrators, and educationalists. Based on the average of these exam scores, teacher candidates are ranked and appointed accordingly to different cities, towns or villages by the Ministry of National Examination (MONE) as contracted teachers in primary, secondary or high schools. In the first years of teaching in Turkey, there is no prescribed pattern of support in the form of mentoring or officially embedded in-service training. After three years of service, novice teachers obtain the official right to become permanent teachers in the MONE system and can apply to change their schools.

\subsection{Participants}

Thirty-four novice English language teachers in total participated in this study voluntarily. The English teachers who were in the first three years of their profession were selected for the study through purposive sampling technique. They all gave their consent willingly and understood that their agreement to participate entailed using their data for research purposes only. They were also informed that they could withdraw from the study at any time, which two participants from Poland actually did. We were finally left with 23 Turkish and 11 Polish novice teachers. They were working with K-12 learners in culturally, socially, economically and historically diverse regions of Turkey and Poland. There were 4 males and 30 females aged from 20 to 40. The teachers worked in the Pomeranian region in Poland and the Central Anatolia, Eastern, South-Eastern and Marmara regions in Turkey. They were graduates of English language teaching programmes of large Turkish state universities and one small university in the north of Poland.

\subsection{Data Collection Procedures and Analysis}

The data were simultaneously collected in both countries during the spring term of 2017 by two teams of researchers (two researchers from Turkey and two from Poland). The data came from two sources: critical incidents of the novice teachers and online 
and/or oral semi-structured interviews in English with these teachers. Using critical incidents helped us understand how the novice teachers made sense of their initial years of teaching in their local contexts (Coldron \& Smith, 1999; Orland-Barak \& Maskit, 2011; Sisson, 2016).

Defined as any unanticipated, meaningful and vividly remembered event that occurs during or outside the class (Tripp, 1993), critical incidents are considered vital in teachers' reflective practices (Farrell, 2012). They reveal teachers' pre-existing knowledge, challenges and coping strategies (Lister \& Crisp, 2007; Richards \& Farrell, 2005), and provide a deeper level of reflection that goes beyond a detailed description of an event to analyse and reflect on the meaning of the event. Tripp (1993) emphasizes that "analyses and reflections assist teachers in examining the possibilities of effective dealing with problems as well as identifying the assumptions governing their actions" (pp. 24-25). By linking teachers' past experiences to their present conditions, critical incidents are also used to understand how teachers make sense of who they are and how they relate to others (Coldron \& Smith, 1999; Sisson, 2016). Therefore, teachers' social experiences of the time and environment in which they live can be successfully explored through critical incidents. The critical incident analysis guideline questions were employed from Tripp's study (1993) (See Appendix). These questions were assigned online via e-mail as weekly written entries. The novice English teachers responded to the questions and reflected on the challenges they experienced in their classrooms. The critical incidents helped them gain a deeper insight and understanding regarding what they do in the classroom. All interviews were conducted separately with each participant and lasted approximately 25 minutes. These interviews functioned as follow-up tasks to the critical incident analysis. The critical incidents, quoted in this study, are the verbatim records of novice English teachers' recollection of critical incidents. Following Tripp (1993), the teachers were asked to increase the details of the incidents so that we could have a clearer sense of them. All participants were given pseudo names for ethical reasons.

In this exploratory study, a comprehensive cyclical data analysis approach was employed (Patton, 2002). We started with open coding of initial categories in the first round of investigation. The second round of data analysis was carried out two months later and lasted until the joint emerging themes and categories were identified. In the semi-structured interviews, we asked each participant to describe their coping strategies, other stakeholders, and their attributions of the events. Some of these questions were: "How do the incidents contribute to your understanding of becoming a teacher in a remote area?", "What suggestions do you have for $4^{\text {th }}$ year pre-service teachers upon these challenges?", "What did you need most while trying to cope with this challenge?". The interviews were transcribed verbatim and read iteratively. The second coding was carried out for interrater reliability. We coded and calculated reliability across $100 \%$ of the dataset. In the case of disagreement, the coders conferred, explained the rationale underlying each of their judgements, and then reached a joint decision. Inter-rater score was assessed by dividing the total number of agreements by the number of agreements, plus disagreements (Miles \& Huberman, 
1994). When a careful reading of the data was made several times and the level of reliability was $90 \%$, we were confident that the emergent themes reflected the participants' meanings.

\section{Results}

We identified the challenges that novice language teachers experienced in their local contexts. We also examined how these teachers developed professionally in the early years of their teaching.

\subsection{Similar challenges in the Turkish and Polish contexts}

\subsubsection{Difficulty in choosing age and language appropriate teaching materials}

This theme emerged out of the data related to the problems in choosing age and language proficiency appropriate teaching materials in their classrooms. These issues were usually centred around the use of intercultural materials, communicative activities and the adaptation of the course book activities in teaching English that were useful for increasing students' motivation. Difficulties in preparing the lesson according to students' interests and age group and providing cultural variety in the selection of topics according to students' diverse backgrounds were likewise reported as challenges by the participating teachers in both groups. The teachers also emphasized the importance of learning English as a medium of communication for future career opportunities; yet, some students were unwilling to learn the L2. In the critical incidents below, novice English teachers explained their reflections on these practices and contributions to their professional development:

"I used sitcoms and movies from different cultures every two week to develop $8^{\text {th }}$ graders' listening comprehension in the target language. I'm happy to see that they are interested in learning new life styles can understand the main idea in the dialogues despite their low proficiency levels. I think the use of intercultural materials contributes to students' openness and understanding different lifestyles" (Turkish participant Ali).

"I chose 'politics' as a debate topic with prep level young adults in one of the English speaking classes. However, the debate turned into a fight and I could not do anything to stop them. Then, I thought that I needed to be more careful while choosing topics and be more sensitive to their profile" (Turkish participant Zeynep).

"One of the $1^{\text {st }}$ graders thought that he was a wolf and was barking in the class. I was desperate and unsuccessful in capturing his attention during the lesson. So, I talked to the school counsellor and the class teacher. Together we figured out that he loved fiction books and decided to choose teaching materials accordingly I came to the point that first I needed to understand the problem deeply" (Turkish participant Rana). 
"By considering students' feedback I adapted activities in the course book and taught "the food" unit. I witness that teachers can increase student motivation by considering students' cultures and expectations" (Polish participant Danuta).

While Turkish teachers focused on challenges stemming from their students' limited English proficiency levels and managing the class while conducting tasks in the class, Polish teachers' challenges centred around increasing students' motivation and integrating technology to make the lessons more enjoyable.

\subsubsection{Difficulty in managing classrooms}

We identified two sub-topics in the Polish and Turkish contexts, concerning the reasons for classroom management from students' and teachers' perspectives: student misbehaviour and teacher attitude. In student misbehaviour, various problems are included, such as smoking electronic cigarettes, cheating on the exams, violating classroom rules, gender discrimination, and verbal harassment. At the end of the school year, teachers' emphases started to shift towards the ways of coping with the types of student misbehaviour rather than complaining about them. These incidents are observed in two contexts as below based on the critical incidents provided by the teachers:

" $8^{\text {th }}$ graders in my English class behaved me rude as a female teacher despite the fact that they were quite silent and attentive in a male teacher's class. They neither listened to me nor respected my words. I talked to the counsellor and the head of the school and learnt that teachers' gender shaped students' behaviours in either positive or negative ways in this village. Males were seen superior compared to females in their home. I think educating students about the gender equality is a necessity in primary and secondary schools in each subject to emphasize the importance of being respectful in the society" (Turkish participant Merve).

"In a mixed-level class of 8 students in a primary school in Poland it is difficult to maintain the discipline because students did not take me seriously and violated the classroom rules. I was very angry and desperate at first. One day, I silently waited in the classroom. This took their attention and they became aware of the misbehaviour. Such a case is very common in rural Poland" (Polish participant Marta).

"Teacher attitude" comprised problems stemming from the inexperience of the teacher. The data contained several examples of participants' attitude with no intention of upsetting students, yet followed by a developing sense of responsibility to, perhaps, make up for the misunderstanding that their attitudes caused. In the critical incidents below, Turkish and Polish participants described how their attitudes in the classroom caused misunderstanding by the students, and how their self-awareness contributed to their understanding of relationships with the students:

"I couldn't remember one of the students' name and addressed him as "hey, the boy with curly blonde hair!". He was astonished but I couldn't estimate how hurtful it was for him. He was in teenage years and wanted to be taken seriously. 
This event caused me to question my empathy skills and increased my selfawareness. I read psychology books on teenagers. I talked to the school counsellor and tried to contact the boy one to one. While preparing my lessons, I should consider groups, students and management techniques beforehand" (Turkish participant Yasemin).

"I use homework as a punishment [as an attitude of the teacher in dealing with naughty students] with primary school learners. I got very angry with their naughty behaviours. I'm aware that I need to develop effective coping strategies instead of punishing them via homework" (Polish participant Roman).

A Turkish participant questioned herself upon a discipline problem, which deepened her perspective on the teacher's role: "Rules should be established from the beginning by considering students' decisions". In the face of student resistance to learning a foreign language, another Turkish participant, Aylin, stated: "Such problems enabled me to question my roles and skills as a teacher and let me take precautions for specific situations in the long run". Although classroom management problems were generally resolved positively, the participants narrated that both devising solutions and deepening perspectives on their roles were difficult.

As a coping strategy, arranging parent-teacher meetings also helped the teachers in both contexts overcome some of the problems. Polish teachers arranged such meetings to inform the parents that the students did not do homework regularly or misbehaved in the classroom. Turkish teachers, however, organized such meetings primarily in rural areas in order to inform the parents that their children devalued the importance of learning a foreign language, which was related to their illiteracy in the mother tongue and, as a result, low English proficiency level. So, while Turkish teachers were focusing on the underlying causes of student misbehaviour in these meetings, Polish teachers detected the problem and shared them with the parents to take precautions against.

\subsection{Different challenges in the Turkish and Polish contexts}

Unlike the Polish participants, the Turkish teachers had challenges resulting from the students' diverse ethnic backgrounds and their mother tongue interference. Most of the time, their students remained silent due to several reasons. The students were not literate in the official language (Turkish); they could not speak Turkish. For example, the lack of language proficiency, even though they were in the upper grades, low motivation to use English, fortified by the poor economic or social conditions in the neighbourhood or their parents' negative attitudes towards English, or the clash between the high-stake examination system and the teaching practices in the classroom are the mainly mentioned reasons in the Turkish teachers' incidents. Hence, the underlying reasons for students' negative attitudes and their unwillingness to learn English vary in both contexts. In this sense, Turkish and Polish teachers show differences in focusing on the reasons for the same challenge as presented in incidents below: 
" $5^{\text {th }}$ grade students in a village in Southern Turkey were resistant to learning new topics such as tourism, culture, festivals in English. I was shocked by the prejudices students had against cultural differences. I think English is not only a subject but also a new perspective towards life. So, we should never give up integrating intercultural elements in English lessons" (Turkish participant Sezen).

"In a parents' meeting, I realised that parents in the region [eastern Turkey with ethnically diverse populations] did not want their children to learn either the foreign (English) or the official (Turkish) language. I learnt that these students were illiterate in Turkish, so had difficulty in reading and writing in English. In some classes, the effect of parents' such views can be clearly seen in the behaviour and attitude of the students. They may ignore the activities, avoid communicating with the teacher, or talk in their mother tongue which is also foreign to the teacher. So, it becomes impossible to reach out to these students or collaborate with parents" (Turkish participant Selin).

Overall, the Turkish participants critically narrated difficulties in teaching students from ethnically diverse backgrounds in rural areas. Resolutions such as the necessity of teacher collaboration, consistency in determining school rules, awareness of students' backgrounds and their previous learning experiences emerged as lessons learnt by them. Such resolutions helped the teachers increase their adaptation to contextual differences and, thereby, their confidence in becoming the kind of teacher they needed to be.

On the contrary, students' attitude to English is on the whole positive when compared with other school subjects in Poland. Issues related to culture and tourism in English course books are rather well received as for most Polish students English is associated with another EU country (England, Scotland, Ireland) where they may have their family members who have worked or are working. However, the challenge for Polish novice teachers is motivating students and teaching mixed-level classes as displayed in above cases with Danuta, Marta, and Roman.

\subsection{How do novice teachers develop their professional understanding?}

The use of critical incidents in this study triggered further self-questioning and recognition of the contextual factors in adapting to the early years of teaching. The participants monitored themselves as teachers and the incidents helped them become aware of different aspects of teaching and their own strengths as teachers. The teachers also had the opportunity to better understand the teaching methodology that they felt successful and/or unsuccessful as a teacher. As a result, they reflected on the teaching-learning moments by learning and relearning from the experiences in their first years. 


\subsubsection{Understanding differences}

Encountering unexpected problems (prejudices against cultural differences, illiterate students in the official language, parents' attitude) followed by the participants' feelings such as shock, frustration, or prejudices with ethnically diverse students and searching for ways to solve them with reference to age-specific characteristics increased their understanding of the social, cultural, and economic issues of the teaching environment. A Turkish teacher revealed an emerging understanding of her students' social environment in the following critical incident:

“The village didn't show respect toward females. I understood that the social and cultural background of students affected students' behaviour with peers and teachers negatively" (Turkish participant, Murat).

In the critical incidents, socialisation with different local people and efforts to facilitate learning conditions of students in less developed regions strengthened novice teachers' determination to do their best in their profession.

\subsubsection{Awareness raising}

Narrating the incidents in this study helped the participating teachers raise their awareness on the source of the problems that may seem ordinary for anyone, and on the resolutions they developed within time. One of the Turkish participants stated that: "My awareness on teaching a foreign language requires time and consistency". Another Turkish participant focused on the reason for the students' illiteracy, claiming that: "In multi-grade classes in small villages students cannot have enough scaffolding opportunity to develop their reading and writing, so they suffer from basic literacy problems". Similar to the Turkish teacher's awareness on the source of the problem, a Polish participant highlighted the need for collaboration with the homeroom teacher to handle classroom problems at primary levels. Hence, the awareness teachers developed was considering precautions for future student behaviours.

\subsubsection{Improving teaching practice}

Teachers disclosed their difficulties with problems such as capturing student attention, choosing age-appropriate games, adapting self-teaching techniques to student learning styles and teaching successfully in underdeveloped regions. To illustrate, three Polish participants described prerequisites for being a successful teacher in Poland: “... a good teacher should first consider the needs and opinions of students, and get prepared for the lesson accordingly” (Polish participant, Andrzej); "patience and professional attitude towards the classroom problems" (Polish participant, Joanna); and "primary levels needed special attention and understanding, so assessing young learners should be made on their individual skills" (Polish participant, Gosia). The teachers revealed their coping strategies for the challenges they faced. While they were discovering these strategies, the experience of understanding differences, awareness raising and learning teaching emerged. 


\section{Discussion}

This study aimed to investigate the challenges Turkish and Polish novice English teachers went through in their initial years of teaching experience and how critical incidents contributed to novice teachers' professional understanding. The challenges narrated in this study emerge from local working conditions in both contexts, so they are specific to novice teachers' understanding the profession and meaning making process. However, when the contribution of the incidents on novice teachers' wider professional changes is considered, it becomes obvious that local challenges help them broaden their global perspectives.

As revealed in other studies (Farrell, 2008; Madalinska-Michalak \& Bavli, 2018; Meristo, Ljalikova, Lofstrom, 2013; Orland-Barak \& Maskit, 2011), the contexts of the two countries also affect the way the novice teachers develop professionally. As Poland is ethnically homogenous and parents want their children to learn English, the problems of Polish novice teachers were related mostly to classroom management. By contrast, Turkish ethnic diversity, especially in the east, turned out to be as significant as classroom management problems.

Similar to previous studies (Nichols, Schutz, Rodger, \& Bilica, 2017; Pillen et al., 2013), this study also found that many novice teachers were often challenged by classroom management problems. In line with the findings of Alsup (2006, 2019), Cohen (2010), Meristo et al. (2013) and Sisson (2016), it transpired that when they were able to transform a challenging situation into a positive outcome as in the above cases of Danuta, Aylin, and Sezen, they felt successful and defined the process as "steps on the way to become a teacher". In contrast, being unable to cope with the challenges was often related to the conflict of roles and disconnections between their too much focus on the theory at pre-service level and their real experiences at present (Cohen, 2010). These inabilities increased their awareness and determination on the way to becoming a teacher. In order to cope with challenges, they preferred problemfocused coping strategies like the participants in Pillen et al.'s (2013) study.

Similar to the participants in Ruohotie-Lyhty and Moate's study (2016), novice teachers in both contexts referred to the gap between the theoretical knowledge they gained at pre-service level and the practical knowledge they developed through real teaching experience. Novices evaluated their pre-service education through the challenges which they encountered but could not cope alone. Since these Turkish teachers taught mostly in rural parts of the country in their initial years, they expressed the need for skills to teach English in mixed-level and culturally diverse classes. Given the multi-cultural classes due to refugee and migration factors in the Turkish context, novice teachers also suggested the consistent supervision and support from their university supervisors about these issues. In the critical incidents below, Turkish and Polish novice English teachers reflected on the gaps pre-service programmes should fill in different courses for future novice teachers. 
"I feel unsuccessful in teaching English in an eastern village due to students' unwillingness and their mother tongue interference. This is my first year in the profession and I feel desperate. I think fourth-year student teachers should be introduced with the rural teaching conditions in the practicum. The supervisor can use video-recordings of English classes from different regions of Turkey" (Turkish participant, Deniz).

"I teach a mixed-level class with 8 students in a primary school in Poland. I have some difficulties in designing lessons according to these mixed levels. I think preservice programmes should prepare pre-service teachers for mixed-level classes and extra-curricular lessons. This is a very common situation in rural Poland" (Polish participant, Anna).

Contrary to the participants in Meristo et al.'s (2013) study, socialisation with parents and colleagues contributed to the novices' experience of subjective journeys on the way to becoming a teacher in this study. These journeys, though devoid of definite end-points, resulted in opportunities to help them increase awareness, understand the reasons for problems, and improve their teaching practice accordingly in their unique experiences narrated in critical incidents (Sisson, 2016). Cooperation and socialisation with others were remembered as professional development facilitators, which coincides with the findings of Meristo et al. (2013), Pillen et al. (2013) and Akcan (2016). Novice teachers developed their understanding teaching through selfquestioning and transferring their previous learning into new contexts. While they were finding ways to cope with the challenges, they became aware of the reasons for some of their negative classroom experiences. They tailored their own teaching techniques to context-bound conditions and critically reflected on the differences between teaching in their diverse conditions and their previous training. As a result, their suggestions could inform pre-service programmes especially in teaching multicultural and multi-level classrooms (Ben-Peretz \& Flores, 2018; Cohen, 2010; Fantilli \& McDougall, 2009; Kizilaslan, 2012; Madalinska-Michalak \& Bavli, 2018, Werbinska, 2011). Bringing videos of various classrooms to practicum seminar lessons and discussing classroom problems were also reported to be effective, which resonates with Fantilli and McDougall's (2009), and Tavil and Güngör's (2016) work. They advocated the necessity of preparing novice teachers for the needs of students and collaborating with others for guidance and assistance. Although novice teachers regarded their practicum as effective, they lacked exposure to diverse student groups in pre-service preparation. Therefore, on the basis of the incidents in this study, online forums in which novice teachers were provided with space to discuss diverse working contexts were acknowledged (Farrell, 2008; Meristo, et al. 2013; Pillen, et al. 2013; Ruohotie-Lyhty \& Moate, 2016). Finally, informal mentorship relations with university supervisors and experienced colleagues were found crucial in assisting novice teachers in developing their professional understanding.

\section{Conclusion}


This cross-cultural study contributes towards understanding non-native novice English teachers' contextual challenges and suggests several implications for preservice teacher education and on-going professional development. Understanding the role of critical incidents is important as they functioned as data collection and reflection tools in which the teachers' emotions, past and present experiences, and professional understanding were narrated (Sisson, 2016). For teacher educators, guiding novice teachers to give meaning to their experiences through sharing and caring could be helpful. Hence, school-university partnerships and fora in which novice teachers can negotiate local experiences with each other have been proposed as a method to support on-going professional development. Encouraging them to collaborate with colleagues through a forum is also significant for their support (Fantilli \& McDougall, 2009; Farrell, 2008; Pillen, et al. 2013).

We draw on the reflections of Turkish and Polish novice language teachers, using their critical incidents as a data collection and reflection tool. The critical incidents collected as part of the project are transformed into a workbook for fourth year student teachers to be used in practicum courses at a pre-service level to help them realize the realities of the working conditions in both countries. In other words, we compiled a workbook both for pre- and in-service language teachers which presented the cases from diverse classroom contexts (Akcan \& Güngör, 2018). The workbook has been used both in in-service teacher education workshops and practicum courses in teacher education programmes. It was published last year and became very popular.

The findings of the study also suggest that creating reflective learning contexts may help novice teachers adapt to their school settings and succeed in developing their analysing and problem-solving skills. It is the case that, thanks to systematic reflection on their experiences, novice teachers can improve their understanding of the diverse issues which are encountered in the initial years of teaching.

\section{Acknowledgements}

This article is produced as part of the Erasmus + project titled ILTERG, "International Language Teacher Education Research Group" (no: KA203-035295) funded by the Turkish National Agency. The study is conducted by Gazi, Boğaziçi, and Pomeranian Universities as partners of the project.

\section{References}

Akcan, S. (2016). Novice non-native English teachers' reflections on their teacher education programmes and their first years of teaching. PROFILE: Issues in Teachers' Professional Development, 18(1), 55-70.

Akcan, S., \& Güngör, M.N. (2018). A workbook for prospective language teachers: challenges from diverse classroom contexts. Istanbul: Bogazici University.

Alsup, J. (2006). Teacher identity discourses. Mahwah, NJ: LEA.

Alsup, J. (2019). Millennial teacher identity discourses. New York, NY: Routledge.

Ben-Peretz, M., \& Flores, M. A. (2018). Tensions and paradoxes in teaching: implications for teacher education. European Journal of Teacher Education, 41(2), 202-213. 
Cochran-Smith, M. (2004). Editorial: The problem of teacher education. Journal of Teacher Education, 55(4), 295-299. http://dx.doi.org/10.1177/0022487104268057.

Cohen, J. L. (2010). Getting recognised: Teachers negotiating professional identities as learners through talk. Teaching and Teacher Education, 26(3), 473-481.

Coldron, J., \& Smith, R. (1999). Active location in teachers' construction of their professional identities. Journal of Curriculum Studies, 31(6), 711-726.

Copland, F., Garton, S., \& Burns, A. (2014). Challenges in teaching English to young learners: global perspectives and local realities. TESOL Quarterly, 48(4), 738-762.

Darling-Hammond, L. (2017). Teacher education around the world: what can we learn from international practice? European Journal of Teacher Education, 40(3), 291-309.

Fantilli, R. D., \& McDougall, D. E. (2009). A study of novice teachers: challenges and supports in the first years. Teaching and Teacher Education, 25(6), 814-825.

Farrell, T.S. (2008). Critical incidents in ELT initial teacher training. ELT Journal, 62(1), 310.

Farrell, T. S. C. (2009). The novice teacher experience. In A. Burns \& J. C. Richards (Eds.), The Cambridge Guide to Second Language Teacher Education (pp. 182-189). New York, NY: Cambridge University Press.

Farrell, T. S. C. (2012). Novice-service language teacher development: bridging the gap between pre-service and in-service education and development. TESOL Quarterly, 46(3), 435-449. http://dx.doi.org/10.1002/tesq.36.

Kizilaslan, I. (2012). Teaching in rural Turkey: pre-service teacher perspectives. European Journal of Teacher Education, 35(2), 243-254.

Kırkgöz, Y. (2014). Türkiye'de yabancı dil eğitim politikaları ve müfredat programı. In S. Akcan \& Y. Bayyurt (Eds.), 3. Ulusal yabancı dil eğitim kurultayl: Türkiye'deki yabancr dil eğitimi üzerine görüş ve düşünceler, konferanstan seçkiler (pp. 45-59). Istanbul: Bogazici University.

Lister, P. G., \& Crisp, B. R. (2007). Critical incident analyses: a practice learning tool for students and practitioners. Practice, 19(1), 47-60.

Madalinska-Michalak, J., \& Bavli, B. (2018). Challenges in teaching English as a foreign language at schools in Poland and Turkey. European Journal of Teacher Education, 41(5), 688-706.

Mann, S., \& Tang, E.H.H. (2012). The role of mentoring in supporting novice English language teachers in Hong Kong. TESOL Quarterly, 46(3), 472-495.

Meristo, M., Ljalikova, A., \& Löfström, E. (2013). Looking back on experienced teachers' reflections: how did pre-service school practice support the development of self-efficacy? European Journal of Teacher Education, 36(4), 428-444.

Miles, M. B., \& Huberman, A. M. (1994). Qualitative data analysis: An expanded sourcebook. Sage.

Nias, J. (1996). Thinking about feeling: the emotions in teaching. Cambridge Journal of Education, 26(3), 293-306.

Nichols, S.L., Schutz, P.A., Rodgers, K., \& Bilica, K. (2017). Early career teachers' emotion and emerging teacher identities. Teachers and Teaching, 23(4), 406-421. DOI: 10.1080/13540602.2016.1211099

Orland-Barak, L., \& Maskit, D. (2011). Novices 'in story': what first-year teachers' narratives reveal about the shady corners of teaching. Teachers and Teaching, 17(4), 435-450, DOI: $10.1080 / 13540602.2011 .580520$

Patton, M. Q. (2002). Qualitative research and evaluation methods (3 $3^{\text {rd }}$ ed.). Thousand Oaks, CA: Sage. 
Pillen, M., Beijaard, D., \& Brok, P. (2013). Tensions in beginning teachers' professional identity development, accompanying feelings and coping strategies. European Journal of Teacher Education, 36(3), 240-260. DOI: 10.1080/02619768.2012.696192

Richards, J. C., \& Farrell, T. S. C. (2005). Professional development for language teachers: Strategies for teacher learning. Ernst Klett Sprachen.

Ruohotie-Lyhty, M., \& Moate, J. (2016). Who and how? Preservice teachers as active agents developing professional identities. Teaching and Teacher Education, 55, 318-327.

Sisson, J. H. (2016). The significance of critical incidents and voice to identity and agency. Teachers and Teaching, 22(6), 670-682.

Tavil, Z. M., \& Güngör, M. N. (2017). A sociocultural perspective on the development of Turkish pre-service teachers' competences and qualifications. Pedagogy, Culture \& Society, 25(2), 263-277.

Tripp, D. (1993). Critical incidents in teaching. London: Routledge.

Veenman, S. (1984). Perceived problems of beginning teachers. Review of Educational Research, 54(2), 143-178. http://dx.doi.org/10.3102/00346543054002143

Werbinska, D. (2011). The first year in the classroom: Crossing the Borderland from being a student to being a teacher. In M. Pawlak (Ed.) Extending the boundaries of research on second language learning and teaching. (pp.181-196). Heidelberg: Springer.

\section{Appendix A. Critical Incident Analysis Framework (taken from Tripp, 1993)}

1. Account of the incident

- What happened, where and when; who was involved?

- What was your role/involvement in the incident?

- What was the context of this incident, e.g. previous involvement of yourself or other from this agency with this client/client group?

- What was the purpose and focus of your contact/intervention at this point?

2. Initial responses to the incident

- What were your thoughts and feelings at the time of this incident?

- What were the responses of other key individuals to this incident? If not known, what do you think these might have been?

3. Issues and dilemmas highlighted by this incident

- What practice dilemmas were identified as a result of this incident?

- What are the values and ethical issues which are highlighted by this incident?

- $\quad$ Are there implications for inter-disciplinary and/or inter-agency collaborations which you have identified as a result of this incident?

\section{Learning}

- What have you learned, e.g. about yourself, relationships with others, the social work task, organisational policies and procedures? 
- What theory (or theories) has (or might have) helped develop your understanding about some aspect of this incident?

- What research has (or might have) helped develop your understanding about some aspect of this incident?

- How might an understanding of the legislative, organisational and policy contexts explain some aspects associated with this incident?

- What future learning needs have you identified as a result of this incident? How might this be achieved?

\section{Outcomes}

- What were the outcomes of this incident for the various participants?

- $\quad$ Are there ways in which this incident has led (or might lead to) changes in how you think, feel or act in particular situations?

- What are your thoughts and feelings now about this incident?

\section{Copyrights}

Copyright for this article is retained by the author(s), with first publication rights granted to the Journal.

This is an open-access article distributed under the terms and conditions of the Creative Commons Attribution license (CC BY-NC-ND) (http://creativecommons.org/licenses/by-nc-nd/4.0/). 